\title{
Volumetric - Spatial design and daylight in apartment buildings. Study case: Havana City.
}

\author{
D. González Couret ${ }^{1, *}$, D. F. Abreu de la Rosa ${ }^{2}$ \\ ${ }^{1,2}$ Faculty of Architecture, ISPJAE, Havana, Cuba \\ *Tel: +53 7 2607242, E-mail: dania@arquitectura.cujae.edu.cu
}

\begin{abstract}
The relationship between architectural shape and daylight is very well known. The geometry of the building and its context influence quantitatively and qualitatively indoor natural illumination. But this architectural feature highly determines also the thermal environment and sometimes these two requirements are contradictory.

The results presented in the paper are part of a wider research that intends to evaluate the influence of the transitional spaces (indoors - outdoors) on the interior spaces environment. In order to do that, measurements of temperature and humidity have been carried out in housing buildings in some urban areas in Habana City, and at the same time, daylight conditions in those buildings and spaces have been simulated. The results of this computer simulation and its discussion are presented in the paper, focused on the performance of the geometry of these transitional spaces.
\end{abstract}

A representative sample of apartment buildings typologies that are being studying in different urban areas was selected in order to simulate daylight performance indoors, using the professional software "DIALux". The better daylight conditions are got in spaces related to wide streets. On the contrary, small yards are not enough, depending on its proportions.

Keywords: Daylight, Simulation, Architectural design, Apartment buildings.

\section{Introduction}

Taking advantage of the urban land is an essential condition to a sustainable built environment. That's why many developed countries are intending to increase density in cities. On the other hand, conservation of traditional urban centers is another important requirement in order to pass to the future generations the historical legacy of each society.

Related to that, the National Institute of Physical Planning in Cuba is promoting the integral rehabilitation of traditional cities, and a departing point for what should be the insertion of new housing buildings in the available plots. But how should these new housing building be? What architectonic references should be taken?.

During the 60's and the 70's, mostly new urbanizations were developed out of the traditional urban grid, using block type building by repetitive projects in open urban areas. When no repetitive projects were built in the consolidated urban zones during the 80's in Havana, the mistakes committed [1] showed the lack of knowledge about the traditional repertory of apartment buildings preexisting in these urban contexts. Finally, the last two decades has been characterized by disperse low density urbanizations that generate a disproportioned and unsustainable urban growing.

Then, projecting and constructing new apartment buildings in traditional urban centers is unavoidable as part of their integral rehabilitation process and for that, it is necessary to know the wide precedent repertory of buildings integrated to the context and conforming the city, to take them as references of the good practices to be recovered and the mistakes to be avoided. 
Several researches have been carried out in the Faculty of Architecture of Havana during the last ten years, driven to characterize the repertory of existing apartment buildings in the traditional urban centers and to evaluate their performance according to the quality of the thermal and luminous indoor environment, taking into account besides, the inhabitant's perception.

The results of the evaluation of the volumetric and spatial solution of apartment buildings existing in three different urban contexts of Havana City according to their influence on indoor daylight are specifically presented in this paper.

\section{Methodology}

In order to evaluate the influence of the building volumetric - spatial design on the indoor daylight levels, real spaces were selected from the study sample composed by 279 apartment buildings located in three different context in Havana City (Centro Habana, El Vedado y Miramar) [2], to simulate interior daylight. The selected spaces are related to outdoors in different ways, according to the volumetric - spatial solution of the building and the urban context.

Indoor daylight depends on several variables. The geometry of the transitional space between indoors and outdoors is the one to be evaluated in this work, which determines the exposition angle to the sky and to direct daylight $\left(\mathrm{e}_{0}\right)$, and also to the light reflected by the exterior elements in the context $\left(\mathrm{e}_{\mathrm{e}}\right)$.

The interior daylight level is also influenced by the reflection coefficient of the surfaces (indoor or outdoor ones), the window area, its location, proportions and type of enclosure (the windows itself) and color, that determine the reduction coefficient for daylight incoming. In order to isolate the studied variable (the transitional space geometry), the rest of the variables were cancelled, assuming the same values or features in all the simulated cases.

The volumetric - spatial design solution was characterized by angles (horizontal and vertical) that determine the exterior geometry respect to the exposed façade of the indoor space to be evaluated. Each way of indoor - outdoor relationship was identified by the angles, the surface that they determine (closed or open) and one dimension, since having only one dimension and the proportions (angles), it is possible to get the characterization of the whole geometry Indoor - outdoor relationship ways were classified in precedent researches [3]:

- To the streets: main streets $(15 \mathrm{~m})$ and secondary ones $(6 \mathrm{~m})$, considering longer dimensions as exceptional.

- To corridors, parallel or perpendicular to the street, belonging to the building itself, it means, inside its volume, as part of the architectural solution.

- To lateral, back and surrounding corridors: open spaces (without roof) annexed to the building as port of the urban context.

- To internal yard: open spaces (without roof) located to the interior of the plot, with width between $1.7 \mathrm{~m}$ and $4.0 \mathrm{~m}$, and length between $4.0 \mathrm{~m}$ and $26.0 \mathrm{~m}$.

- To lateral yard: open spaces (without roof) located to the interior of the plot, but laterally, where one of the dimensions is considerably larger than the other, with width between $1.0 \mathrm{~m}$ and $6.0 \mathrm{~m}$ and length between $9.0 \mathrm{~m}$ and $25.0 \mathrm{~m}$.

- To small yards ("patinejos" or wind boxes): open spaces (without roof), but closed in their four vertical surfaces, located to the interior of the plot, with smaller dimensions than the yards (width between $0.5 \mathrm{~m}$ and $1.7 \mathrm{~m}$, and length between $1.2 \mathrm{~m}$ and $4.0 \mathrm{~m}$ ). 
- To "grecas": open space (without roof) similar to small yards, but also open by one of the vertical surfaces.

Departing from this detailed classification, only three general types of transitional spaces have been identified for the simulation, according to the geometric characterization: corridor (Figure 1), yard and “greca” (Figure 2).

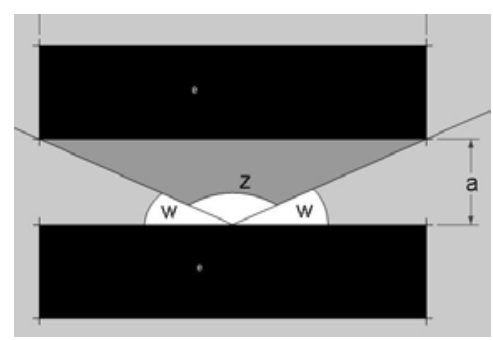

Street and corridor

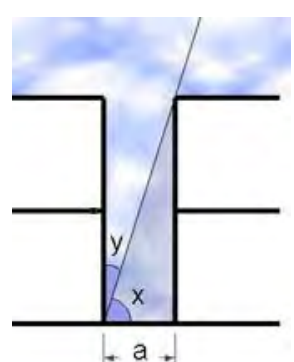

Corridor section

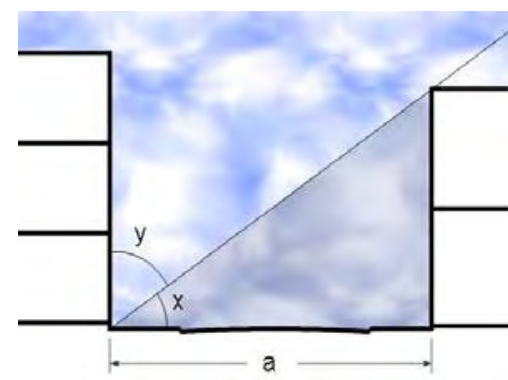

Street section

Fig. 1. Corridor type spaces: closed in the front and open laterally (corridors and streets).

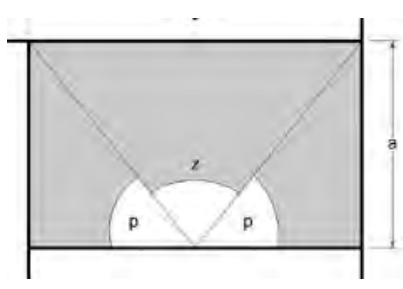

Yard Plan

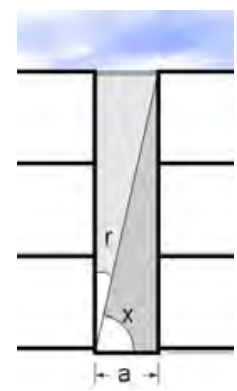

Yard Section

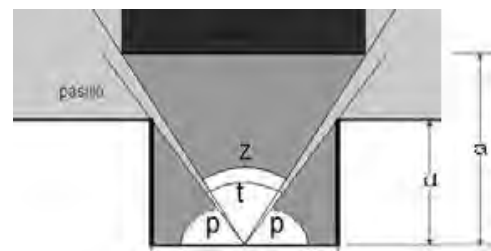

Greca Plan

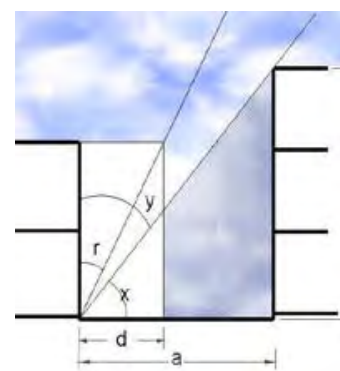

Greca Section

Fig. 2. Yard and Greca type spaces

Where X: frontal obstruction angle in section; $\mathrm{Y}$ : angle of opening to the sky in section $(\mathrm{x}+\mathrm{y}$ $\left.=90^{\circ}\right)$; Z: frontal obstruction angle in plan; $\mathrm{W}$ : lateral opening angle in plan $\left(\mathrm{z}+2 \mathrm{w}=180^{\circ}\right)$; $\mathrm{r}$ : lateral obstruction angle in section; t: frontal opening angle in plan; p: lateral obstruction angle in plan $\left(\mathrm{t}+2 \mathrm{p}=180^{\circ}\right)$; a: distance from the angle origin to the frontal obstruction surface.

\subsection{Study cases}

Taking into account this geometric characterization of the transitional in - out spaces, 44 spaces were selected from the repertory of apartment buildings studied in precedent researches, representatives of each of the three urban context considered (Centro Habana, El Vedado and Miramar), and of each transitional type, including diverse orientations.

Despite orientation was taken into account to select the study cases (because of its influence in the thermal environment studied in other parallel research), this variable was not considered in the simulation of daylight performance, since the used software departs from a uniform sky to determine the daylight factor. 
The spaces selected in Centro Habana are related to outdoors by streets and yards, streets with different sections (proportions) and orientation, and yards with extreme proportions. In El Vedado and Miramar, the spaces selected are related to yards, corridors and "grecas". (Table 1)

Table 1. Study Cases, according to type of transitional space and urban context.

\begin{tabular}{lcccc}
\hline \multicolumn{1}{c}{ Urban Context } & Corridor & Yard & Greca & Total \\
\hline Centro Habana & 6 & 8 & - & 14 \\
El Vedado & 8 & 8 & 1 & 17 \\
Miramar & 4 & 4 & 5 & 13 \\
\hline Total & 18 & 20 & 6 & 44 \\
\hline
\end{tabular}

\subsection{Software}

Four software were evaluated to simulate indoor daylight performance: DIALux 4.6 (2007), Ecotect (2007), Relux (2007), Adeline (1998), by comparing the results achieved with each of them to real values measured by De la Peña in 1986 [3] in a living room rectangular in plant $(5.2 \mathrm{~m} \times 3.6 \mathrm{~m})$ with unilateral daylight through a balcony, locating the luxometer in the center of the space. The daylight factor achieved in the measurement was 0.56 .

In order to simulate daylight using Dialux 4.6 a transference coefficient for windows was considered as 0.90 (glass windows), reflection coefficients for ceiling, walls and floor as 0.70 , 0.50 and 0.20 respectively, and the sky type was assumed as uniform, according to the model defined to Havana. The daylight factor (e) was simulated on a surface located $0.75 \mathrm{~m}$ over the floor, and the point located in the middle of the space was used to compare to the real measurements. The coincidence between the values simulated and measured $(e=0.56)$ confirms the possibility of using Dialux 4.6 for interior daylight simulation. Dialux 4.6, besides, allows making the model of the space easily, quickly and with high precision, and offers numerical and graphic results with high quality renders.

\subsection{Simulation}

The study cases were considered in extreme conditions, that's why the spaces were located on the ground floor, and the time assumed was December at $4.00 \mathrm{pm}$, the more critical for indoor daylight.

Dialux 4.6 considers an overcast sky that corresponds to the uniform sky as a theoretical model, with the same luminance in all directions. The model is appropriate to Havana's sky, defined as partially cloudy, with tendency to be overcast and not permeable to the solar rays, intermittent light and constant luminosity, as an isotropic model with the alternative presence of the sun [4]. Fort the latitude of Havana, in December at $4.00 \mathrm{pm}$ Dialux 4.6 assume diffuse daylight values on an outdoor horizontal plane, equivalent to 10163 lux.

In order to simulate indoor daylight in the selected study cases, a standard space (3.60m by $3.60 \mathrm{~m}$ in area and $2.80 \mathrm{~m}$ in height) was taken, with a louver wooden windows (1.40m wide by $1.20 \mathrm{~m}$ height), white colored and located to the center of the wall, as traditionally used. The reflection coefficients considered to surfaces were: 0.2 to the floor, 0.5 to the ceiling and 0.7 to the walls, as well as 0.5 to the exterior ones, coincident to the values recommended by the software; the windows transmittance was assumed as $36 \%$ and reflectance as $79 \%$ (light color). The values of indoor daylight were considered on a gridded plane located at $0.75 \mathrm{~m}$ height from the floor level. 
The simulation process started with a space directly exposed to outdoors in an open context, which result was compared to the simulation of spaces related to outdoors by different types of transitional spaces with their particular geometry, in order to evaluate the influence of the volumetric - spatial solution on the indoor daylight.

\section{Results}

The results got in the simulation process were summarized in relation to the geometry of the transitional space and the percentage of reduction in comparison to a similar space connected to outdoors without obstruction, where " $a$ " is infinite and " $\mathrm{x}$ " equivalent to $0^{0}$.

The simulated spaces didn't compliment the required daylight level (daylight factor value $=1.5$ for kitchens), and only in one case, the minimum uniformity (0.3) is achieved. The higher daylight levels are got in spaces related to corridors (width streets and the more favorable urban context is Miramar, with lower land occupation. (Table 2)

Table 2. Daylight Factor and Uniformity indoors according to transitional space and context

\begin{tabular}{lcccccc}
\hline Urban Context & \multicolumn{2}{c}{ Corridor } & \multicolumn{2}{c}{ Yard } & \multicolumn{2}{c}{ Greca } \\
& $\mathrm{e}_{0}$ & $\mathrm{U}$ & $\mathrm{e}_{0}$ & $\mathrm{U}$ & $\mathrm{e}_{0}$ & $\mathrm{U}$ \\
\hline Centro Habana & 0.32 & 0.09 & 0.03 & 0.18 & - & - \\
& 0.09 & 0.03 & 0.01 & 0.02 & - & - \\
& 0.46 & 0.15 & 0.02 & 1.00 & - & - \\
& 0.17 & 0.06 & 0.01 & 1.00 & - & - \\
& 0.20 & 0.09 & 0.00 & 0.00 & - & - \\
\hline El Vedado & 0.32 & 0.11 & - & - & - & - \\
& 0.01 & 0.07 & 0.05 & 0.07 & 0.02 & 0.05 \\
& 0.01 & 0.07 & 0.05 & 0.07 & - & - \\
& 0.03 & 0.04 & 0.05 & 0.07 & - & - \\
& 0.03 & 0.04 & 0.05 & 0.07 & - & - \\
& 0.15 & 0.05 & 0.01 & 0.25 & - & - \\
& 0.02 & 0.05 & 0.05 & 1.00 & - & - \\
\hline Miramar & 0.02 & 0.05 & 0.00 & 0.00 & - & 0.05 \\
& 0.02 & 0.05 & 0.00 & 0.00 & - & 0.31 \\
& 0.16 & 0.04 & 0.04 & 0.26 & 0.08 & 0.08 \\
& 0.14 & 0.05 & 0.04 & 0.26 & 0.06 & 0.08 \\
& 0.33 & 0.09 & 0.04 & 0.26 & 0.19 & 0.08 \\
\hline
\end{tabular}

However, the influence of the geometry of the transitional space on the indoor daylight can be evaluated taking into account the reduction of daylight level (in \%) respect to the reference space directly related to an open outdoors.

\section{Discussion and Conclusions}

There is a direct relationship between the type of transitional space and the reduction of indoor daylight. The corridors constitute spaces only closed on the front, but open to the top and laterals. Those spaces, as well as the "greca" type, opened by one of their vertical surfaces 
(frontal or lateral ones) besides the top, are more favorable than yards from the daylight point of view. (Figure 3)

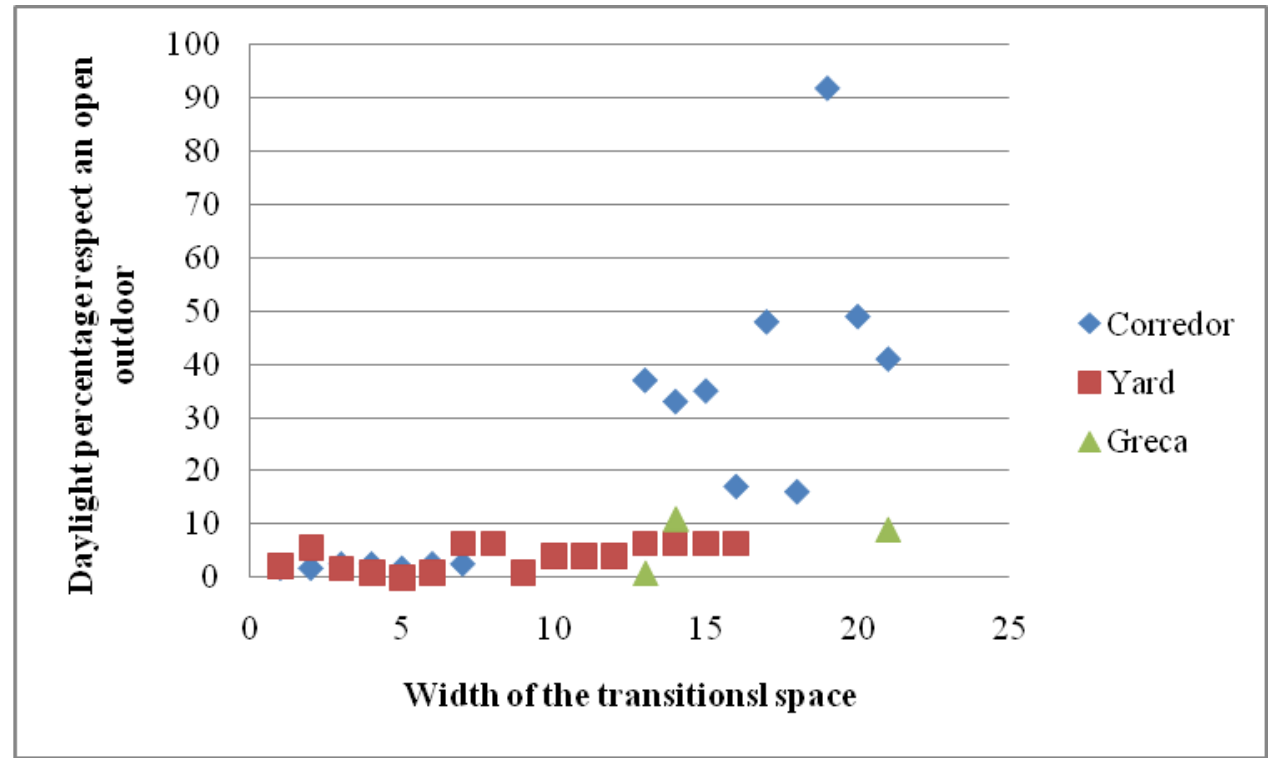

Fig.3. Percentage of daylight in spaces related to each transitional space, respect to a direct relationship to an open outdoors.

Of course, the dimensions and proportions of the transitional spaces also influence indoor daylight that decreases with the reduction of the separation between volumes, it means, with the dimension of the transitional space. In that sense, spaces with width minor than $10 \mathrm{~m}$ reduce daylight levels in more than 50\%. Something similar happen related to the building height that determines the vertical angle (x). With angles over $60^{\circ}$, also indoor daylight decreases to less to the half of the value achieved in relation to an open context $(x=0.0)$.

For the same height of building volume and distances between them, open corridors are better than closed yards respect to daylight.

These results reinforce some conclusions formerly achieved respect to the convenience of reducing land occupation in current compact urban areas and to avoid using small yards to provide daylight and natural ventilation in housing buildings. Next steps in the research requires an evaluation of this transitional spaces also from the thermal point of view, according to the Cuban climate, to get a balance about what could be really more appropriate form an integral point of view.

\section{References}

[1] R. Gómez Briñoles, Edificios multifamiliares en la ciudad de La Habana, Tesis de Maestría en Vivienda Social, Facultad de Arquitectura, ISPJAE, Havana, 2001.

[2] A. Zorrilla Rodriguez, Edificios de apartamentos en la ciudad de La Habana. Tipología de diseño volumétrico espacial, Tesis de Maestría en Vivienda Social, Facultad de Arquitectura, ISPJAE, Havana, 2008.

[3] A.M. De la Peña, Iluminación natural en la vivienda cubana, Revista Arquitectura y Urbanismo No. 3, ISPJAE, Havana, 1986, pp. 40 - 45.

[4] A.M. De la Peña, Iluminación natural en edificios bajo las condiciones de Cuba, Tesis de Doctorado, Facultad de Arquitectura, ISPJAE, Havana, 1992. 